Surgical treatment of early stage breast cancer in the Auckland and Waikato regions of New Zealand.

Ian Campbell, ${ }^{1,2}$ Chunhuan Lao, ${ }^{3}$ Tania Blackmore,${ }^{3}$ Melissa Edwards, ${ }^{1}$ Lou Hayes, ${ }^{2}$ Alex $\mathrm{Ng},{ }^{4}$ Ross Lawrenson ${ }^{2,3}$

${ }^{1}$ School of Medicine, University of Auckland, Auckland, New Zealand; ${ }^{2}$ Waikato District Health Board, Hamilton, New Zealand; ${ }^{3}$ University of Waikato, Hamilton, New Zealand; ${ }^{4}$ Auckland City Hospital, Auckland, New Zealand

Number of tables: 4

Abstract word count: 220

Text word count: 3170

Ian Campbell, lan.Campbell@waikatodhb.health.nz, Associate Professor of Surgery, Waikato DHB, Private Bag 3200, Hamilton 3240, New Zealand, 078398726 ext. 97845. 
Background. The aim of this study was to understand the factors influencing the use of surgical options by New Zealand women with newly diagnosed breast cancer. Method. Using data from the Auckland and Waikato breast cancer registers, we included 11798 women diagnosed with stage I-III breast cancer from June 2000-May 2013. The characteristics of women receiving different surgical treatments and having immediate breast reconstruction following mastectomy were examined. A logistic regression was used to estimate the odds ratio of having breast-conserving surgery (BCS) versus mastectomy and immediate post mastectomy reconstruction. Bilateral breast cancer cases and women with unilateral breast cancer, but who had bilateral surgery, were also identified. Results. Fiftytwo percent of women received BCS and $44 \%$ had mastectomy over the study period. Key influences associated with BCS were age, mode of diagnosis, socio-economic status and public or private treatment. Just under half of women who underwent bilateral surgery did not have bilateral cancer. Nineteen percent of women undergoing mastectomy underwent immediate reconstruction. Implant use increased slightly over the study period but there was a decrease in the use of autologous flap procedures. Conclusion. Surgical management of women with localised breast cancer was generally in line with guidelines, but with potential to further increase use of breast conservation and immediate reconstruction in suitable cases.

Keywords: breast cancer, surgery, New Zealand 
Introduction

New Zealand (NZ) has a population of 4.5 million, of which 1.9 million live in and about the Auckland and Waikato regions. Three thousand NZ women are diagnosed with breast cancer each year. The primary treatment for $95 \%$ of women with localised breast cancer is surgery. Historically, surgical treatment has involved mastectomy ${ }^{1}$, but in 1990 the National Institutes of Health Consensus Conference recommended breast conserving surgery (BCS) followed by radiotherapy (RT) as the treatment of choice for early stage breast cancer in suitable cases $^{2}$. These recommendations led to a steady increase in the uptake of $\mathrm{BCS}^{3}$. More recently, however, rates of mastectomy have been seen to increase in the U.S. ${ }^{4}$, even in women with breast cancer that is suitable for $\mathrm{BCS}^{5}$.

Reasons why women choose BCS or mastectomy are multi-factorial. Factors influencing decision-making include surgeon opinion ${ }^{6}$, tumour size (and size relative to breast size) and location ${ }^{7}$, access to $\mathrm{RT}^{8}$, socioeconomic status and education level ${ }^{9}$, ethnicity ${ }^{10}$, co-morbidity ${ }^{11}$, use of pre-operative MRI ${ }^{4}$, BRCA status ${ }^{8}$ and family history ${ }^{6}$. Fear of recurrent cancer is an important factor driving the uptake of mastectomy, which offers a perception of reduced risk and avoidance of repeat treatments or RT associated with $\mathrm{BCS}^{6}$. In contrast, BCS is perceived as less radical, with a positive cosmetic outcome and body image $^{2,6}$. From a surgical perspective, more women are becoming suitable for BCS with growing training and use of oncoplastic techniques, including reduction or volume replacement techniques.

A small number of women are diagnosed with cancer in both breasts and undergo bilateral surgery - usually bilateral mastectomy. In some cases, women with uni-lateral disease choose bilateral mastectomy to prevent cancer in the other breast ${ }^{5}$, despite no clinical evidence to support any further survival benefit ${ }^{12}$. In addition, an increasing option for women choosing mastectomy is to have immediate breast reconstruction ${ }^{13}$, using either autologous techniques (deep inferior epigastric perforator artery (DIEP) flaps, transverse rectus abdominis myocutaneous (TRAM) flaps and latissimus dorsi (LD) flaps) or implant based reconstruction ${ }^{14}$.

This study examines the different surgical options used in a large cohort of NZ women with newly diagnosed breast cancer, and the sociodemographic and ethnic factors influencing treatment options. 
Methods

This study is based on data from two cancer registers (Auckland and Waikato), which have prospectively collected data from almost $100 \%$ of newly diagnosed breast cancer cases. Data are entered on to the registers through clinic and operation records, multidisciplinary meeting records, oncology, palliative care and private and public hospital records ${ }^{15}$. We included 11798 women diagnosed with stage I-III breast cancer between June 2000 and May 2013, and excluded 574 women with metastatic disease and men with a breast cancer diagnosis. Patient consent to access data from both registers was not required (ethics ref: WAl/04/10/099/AM02).

Information in the combined registers includes (but is not limited to): 1) patient characteristics: age, diagnosis date, mode of diagnosis, socio-economic status, public/private, region (Auckland/Waikato) and ethnicity; 2) tumour biology: cancer stage, grade, and tumour size; 3) treatment: chemotherapy, surgery and radiotherapy; and 4) cancer progression: local recurrence, metastases and date of death. The presence of comorbidities was ascertained by data linkage to the National Minimum Dataset (NMDS) that records clinical data for inpatients and day patients. We characterised patients as having no co-morbidities ( $\mathrm{C} 0)$, one co-morbidity $(\mathrm{C} 1)$ or 2 or more $(\mathrm{C} 2+)$ using the $\mathrm{C} 3$ co-morbidity count $^{16}$.

Surgical choices were categorised as either BCS, mastectomy or no primary surgery. We recorded surgery to one or both breasts, and whether women choosing mastectomy opted for breast reconstruction. Reconstructive surgery was categorised as DIEP/TRAM flaps, LD flaps or implants/expanders. We identified bilateral breast cancer cases and women who had unilateral breast cancer but had bilateral surgeries.

Descriptive statistics for categorical variables are displayed as actual numbers/percentages and compared between groups using Chi square tests. All tests of significance were two tailed, with $\mathrm{P}<0.05$ considered significant. Sociodemographic and disease factors associated with the receipt of BCS (versus mastectomy), as well as the receipt of post-mastectomy breast reconstruction were determined using logistic regression to obtain odds ratios (OR's). All statistical analyses were performed in SPSS version 23 (New York, United States).

Ethical approval for the study was granted through the Northern A Health and Disability Ethics Committee, reference: 12/NTA/42/AM01. 
Results

Primary surgery

Of the 11798 women diagnosed with stage I-III breast cancer between June 2000 and May 2013, 6149 (52\%) women had BCS, 5179 (44\%) had mastectomy, and 470 (4\%) had no primary surgery (Table 1). The probability of having BCS compared to mastectomy was greatest in the screening age range, and decreased with age (Table 2). Women living in the Waikato (OR: 1.60, 95\% Cl 1.44-1.78) and those with screened detected cancers (OR: 2.23, 95\% Cl: 2.04-2.43) were more likely to have BCS. Women treated in a public hospital (OR: 0.70, 95\% Cl: 0.64-0.77), living in the most deprived socioeconomic quintile (9-10) (OR: 0.76, 95\% Cl: 0.66-0.87) and with higher cancer stage (OR 0.36 (95\% Cl: 0.33-0.39) for stage II vs stage I; OR $0.13(95 \% \mathrm{Cl}$ : $0.11-0.15)$ for stage III vs stage I) were less likely to receive $\mathrm{BCS}$.

\section{Breast reconstruction after mastectomy}

After mastectomy, 972 (19\%) women had immediate breast reconstruction: 434 (45\%) DIEP or TRAM flaps, 131 (13\%) LD flaps, and 407 (42\%) implant/expander reconstruction (Table 3). The rate of immediate reconstruction increased from $17 \%$ in $2000-2003$ to $21 \%$ in 2010-2013. Implant/expander reconstruction increased from $12 \%$ in $2000-2003$ to $56 \%$ in 2010-2013, and the use of DIEP and TRAM flaps decreased from 68\% in 2000-2003 to 31\% in 2010-2013.

Logistic regression showed that ethnicity, public/private hospital, having postmastectomy RT, region, cancer stage, co-morbidity, screen detection, age and year of diagnosis had a significant impact on the likelihood of having breast reconstruction following mastectomy (Table 4). The adjusted OR's of having breast reconstruction were $0.53(95 \% \mathrm{Cl}$ : 0.38-0.73) and 0.46 (95\% Cl: 0.31-0.67) for Māori and Pacific women compared to others; 0.43 (95\% Cl: 0.36-0.51) for women treated publically compared to privately; 0.59 for (95\% $\mathrm{Cl}$ : 0.45-0.78) for women living in the most deprived socioeconomic quintile (9-10); 0.76 (95\% $\mathrm{Cl}$ : 0.62-0.92) for those who had RT compared to those who did not; 1.41 (95\% Cl: 1.141.75) for Waikato patients compared to Auckland patients; 0.78 (95\% Cl: 0.64-0.95) and 0.52 (95\% Cl: 0.40-0.68) for women with stage II and III cancer compared to women with stage I cancer; 0.36 (95\% Cl: $0.23-0.57)$ for women with co-morbidity of $2+$ compared to no co-morbidity, and 1.87 (95\% Cl: 1.55-2.26) for women who were screen detected compared to those who were not; 0.91 (95\% Cl: 0.90-0.92) for age; and 1.03 (95\% Cl: 1.01-1.05) for year of diagnosis. An additional 142 women had delayed reconstruction, although this may be an underestimate as plastic surgeon records are not always reported to the registers. 
Bilateral cancer and bilateral surgeries

We found 295 (3\%) women diagnosed with bilateral breast cancer, including 236 from Auckland and 59 from Waikato. Of these, 174 (59\%) women had bilateral mastectomy, $82(28 \%)$ had bilateral BCS, 17 (6\%) had BCS and mastectomy on each side, and $22(8 \%)$ had no primary surgery. After bilateral mastectomy, 51 (29\%) had immediate bilateral breast reconstruction.

There were 290 (2\%) women diagnosed with unilateral breast cancer, but who underwent bilateral surgery, including 242 from Auckland and 48 from the Waikato. Of these, 285 (98\%) women had a bilateral mastectomy. Following bilateral mastectomy, 79 (28\%) had immediate bilateral breast reconstruction. The rates of bilateral mastectomy in women diagnosed with unilateral breast cancer increased over time (1.3\% in $2000-03$ to $3.7 \%$ in 2010-2013). 


\section{Discussion}

Mastectomy is still used in women with primary breast cancer that is potentially suitable for BCS. In this NZ cohort, we found slightly more use of BCS, with $52 \%$ of women receiving BCS while $44 \%$ of women received a mastectomy. More use of BCS is in contrast to reports of a steady rise in the use of mastectomy in the U.S. ${ }^{3,4}$ but is in accordance with Australian BCS rates of $61 \%$ over similar time periods ${ }^{17}$. Women diagnosed through screening, even after adjustment for age and stage, were twice as likely to receive BCS, while only $29 \%$ underwent a mastectomy. In 2004, the eligible age range for screening in NZ was widened to include women 45-49 years in addition to the 50-69 year age group, which could partly explain the slightly higher rate of BCS. We have shown fairly stable rates of mastectomy, slightly higher than the reported rate of $39 \%$ in Australia over a similar time period ${ }^{17}$, higher than U.K. audit data for screen detected cancers of 23\% from 2013/14-2014/15 ${ }^{18}$, and within variable provincial Canadian rates of $26 \%-69 \% 19$.

It has been reported elsewhere that younger women, particularly $<40$ years of age, are more likely to choose mastectomy ${ }^{3,4,5}$. We report similar data, with $61 \%$ of women aged $<40$ opting for mastectomy. Younger women have a higher likelihood of being BRCA gene mutation positive ${ }^{4,5}$ and have a higher risk of local recurrence after BCS. Fear of recurrence has a major influence on decision-making for this age group. Women older than the NZ screening range (45-69) were also more likely to choose mastectomy.

Women living in the Waikato region were more likely to be treated with BCS, even after adjustment for stage, grade and size of tumour. Surgeon or system differences could account for some of the variation in the type of surgery chosen. The level of surgeon influence on women's surgery decisions is a significant factor in published studies ${ }^{3,6,10,20 .}$ Patients treated publicly and those living in the most deprived socioeconomic quintile (9-10) were less likely to receive BCS. Social deprivation likely plays a role in decision-making ${ }^{8,9}$ and lower rates of breast reconstruction ${ }^{21}$ and may also indirectly relate to differences in surgical treatment between the public and private sector ${ }^{10}$.

Only 586 women underwent bilateral surgery, and 290 (50\%) of these did not have bilateral cancer. Bilateral mastectomy reduces the risk of contralateral breast cancer following unilateral disease, but does not increase survival in BRCA1/2 mutation negative women $^{12}$. Reasons why women choose bilateral surgery are related to clinical, psychological and cosmetic outcomes ${ }^{12}$, anxiety surrounding future treatments, family history ${ }^{9}$, and being BRCA or other gene mutation positive ${ }^{22}$. Fear of recurrence and a misperception of enhanced survival are major influences ${ }^{12}$, with younger women more anxious than older women $^{23}$ and therefore more likely to opt for bilateral mastectomy ${ }^{9}, 22,23$. In the current cohort, $80 \%$ of women who had unilateral breast cancer but opted for bilateral surgery were 
$<60$ years of age, and as age increased, the likelihood of having a bilateral mastectomy decreased.

The uptake of breast reconstruction has been increasing slowly over time ${ }^{13}$. In this cohort, immediate reconstruction increased from $17-21 \%$ at the end of the study period. This compares to a rate of $12-16 \%$ in Australia ${ }^{24}$, an average regional rate of $21 \%$ in the $\mathrm{UK}^{25}$ and $26 \%$ in the U.S. ${ }^{26}$. In our study, the crude percentages of reconstruction between the two NZ regions were similar, but the OR for breast reconstruction in the Waikato was $40 \%$ higher than in Auckland after adjusting for greater deprivation and use of post mastectomy radiotherapy in the Waikato. Regional differences can be due to a mixture of patient factors (age, social deprivation), system factors (size and location of treatment facilities) and surgeon preferences (e.g., timing and suitability for reconstruction, and preferred method such as implants alone vs. use of LD flaps). Regional differences have also been reported in the U.S., where up to $84 \%$ of caucasian women in areas with a high density of plastic surgeons, and private insurance, undergo immediate reconstruction ${ }^{27}$.

Women identified through breast screening but who chose mastectomy were also more likely to have reconstruction. There are many possible reasons for this, including, higher health literacy, fewer Māori and Pacific women in this population, and a higher proportion of screened women having tumours that do not require RT, e.g., extensive DCIS. Compared with NZ European, Māori and Pasifika women were significantly less likely to undergo breast reconstruction. Ethnic disparities have been reported previously ${ }^{10}$ and may in part be influenced by factors such as smoking and obesity. Other factors influencing whether women receive reconstruction (but not addressed in this study) include living remotely ${ }^{28}$, surgeon caseloads or large tumour size ${ }^{24}$.

There was a decrease in the use of autologous procedures (DIEP, TRAM and LD flaps) and an increase in the use of implants from $12 \%$ in 2000-03 to 56\% in 2010-13 (Table 3). This trend has also been reported elsewhere ${ }^{29}$ and is likely due to improvements in implant techniques, with growing use of acellular dermal matrices and subsequent use of fat grafting, whilst avoiding the morbidity associated with autologous methods. Autologous procedures also often involve specialist plastic surgical input, which additionally makes the scheduling and timely provision of surgery more difficult.

The relatively large sample is a strength of this study. The sample was derived from generally complete population based datasets. A limitation is that we restricted our analysis on breast reconstruction to immediate surgeries, as we were concerned that there may be an under-recording of delayed surgical intervention. However, we believe the proportion of delayed breast reconstruction is less than $10 \%$ of the total.

This study examines the different surgical options used in a large cohort of NZ women with newly diagnosed breast cancer. We have shown slightly more use of BCS over 
the study period, perhaps explained by the increase in diagnoses through screening. Mastectomy was more likely in older women, but more women in the $<40$ age group were also opting for mastectomy, which is in accordance with trends reported elsewhere. Almost 3\% of women underwent bilateral mastectomy despite having unilateral breast cancer. We report growing rates of immediate breast reconstruction, with an increase in implant based reconstruction techniques. By international standards, there is room for improvement in both breast conservation rates, and use of immediate breast reconstruction.

\section{Declaration of interest}

The authors declare they have no conflict of interest.

\section{Acknowledgements}

We acknowledge the Auckland and Waikato Breast Cancer Registers for providing the data. This work was supported by the Health Research Council of NZ (Grant number 14/484). 


\section{References}

1. Critchley, ACC, Cain, HJ. Surgical techniques in breast cancer: an overview. Surgery, 2016; 34 (1): 32-42.

2. Conference, NC. Treatment of Early-Stage Breast Cancer. JAMA, 1991; 265 (3): 391-395.

3. Kummerow, KL, Du, L, Penson, DF, Shyr, Y, Hooks, MA. Nationwide trends in mastectomy for early-stage breast cancer. JAMA Surgery, 2015; 150 (1): 9-16.

4. McGuire, KP, Santillan, AA, Kaur, P et al. Are mastectomies on the rise? A 13-year trend analysis of the selection of mastectomy versus breast conservation therapy in 5865 patients. Annals of Surgical Oncology, 2009; 16(10): 2682-2690.

5. Bellavance, EC, Kesmodel, SB. Decision-making in the surgical treatment of breast cancer: factors influencing women's choices for mastectomy and breast conserving surgery. Frontiers in Oncology, 2016; 6: 74.

6. Gu, J, Groot, G, Holtslander, L, Engler-Stringer, R. Understanding Women's Choice of Mastectomy Versus Breast Conserving Therapy in Early-Stage Breast Cancer. Clinical Medicine Insights: Oncology, 2017; 11: 1179554917691266.

7. Chagpar, AB, Studts, JL, Scoggins, CR. Factors associated with surgical options for breast carcinoma. Cancer, 2006; 106(7): 1462-1466.

8. MacBride, MB, Neal, L, Dilaveri, CA et al. Factors Associated with Surgical Decision Making in Women with Early-Stage Breast Cancer: A Literature Review. Journal of Women's Health, 2013; 22(3): 236-242.

9. Pesce, CE, Liederbach, E, Czechura, T, Winchester, DJ, Yao, K. Changing surgical trends in young patients with early stage breast cancer, 2003 to 2010: a report from the National Cancer Data Base. Journal of the American College of Surgeons, 2014; 219(1): 1928.

10. Seneviratne, S, Scott, N, Lawrenson, R, Campbell, I. Ethnic, socio-demographic and socio-economic differences in surgical treatment of breast cancer in New Zealand. ANZ Journal of Surgery, 2015; 87: E32-E39.

11. Zhou, J, Enewold, L, Zahm, SH et al. Breast conserving surgery versus mastectomy: the influence of comorbidities on choice of surgical operation in the Department of Defense health care system. The American Journal of Surgery, 2013; 206(3): 393-399.

12. Tesson, S, Richards, I, Porter, D et al. Women's preferences for contralateral prophylactic mastectomy: An investigation using protection motivation theory. Patient Education and Counseling. 2016; 99(5): 814-822.

13. Ilonzo, N., Tsang, A, Tsantes, S, Estabrook, A, Ma, AMT. Breast reconstruction after mastectomy: a ten-year analysis of trends and immediate postoperative outcomes. The Breast, 2017; 32: 7-12.

14. Gradishar, WJ, Anderson, BO, Balassanian, R et al. Breast Cancer Version 2.2015 Clinical Practice Guidelines in Oncology .Journal of the National Comprehensive Cancer Network, 2015; 13(4): 448-475.

15. Seneviratne, S, Campbell I, Scott, N, Shirley, R, Peni, T, Lawrenson, R. Accuracy and completeness of the New Zealand Cancer Registry for staging of invasive breast cancer. Cancer Epidemiology, 2014; 38: 638-644. 
16. Sarfati D, Gurney, J, Stanley, J et al. Cancer-specific administrative data-based comorbidity indices provided valid alternative to Charlson and National Cancer Institute Indices. Journal of Clinical Epidemiology, 2014; 67: 586-595.

17. Roder, DM, Zorbas, $\mathrm{H}$, Kollias, $\mathrm{J}$ et al. Factors Predictive of Treatment by Australian Breast Surgeons of Invasive Female Breast Cancer by Mastectomy rather than Breast Conserving Surgery. Asian Pacific Journal of Cancer Prevention, 2013; 14: 539-545.

18. NHS Breast Screening Programme and Association of Breast Surgery Breast Screening Audit Group. An audit of screen detected breast cancers for the year of screening April 2014 to March 2015. 2016; NHS.

19. Porter, $\mathrm{G}$, Wagar, $\mathrm{B}, \mathrm{Bryant}, \mathrm{H}$ et al. Rates of breast cancer surgery in Canada from 2007/08 to 2009/10: retrospective cohort study. CMAJ Open, 2014; 2(2): E102-E108.

20. Hershman, DL, Buono, D, Jacobson, JS, McBride, RB, Tsai, WY, Joseph, KA, Neugut, Al. Surgeon characteristics and use of breast conservation surgery in women with early stage breast cancer. Ann Surg., 2009; 249 (5).

21. Platt, J, Baxter, N, Zhong, T. Breast reconstruction after mastectomy for breast cancer. CMAJ, 2011; 183 (18): 2109-2116.

22. Fu, Y, Zhuang, Z, Dewing, M, Apple, S, Chang, H. Predictors for contralateral prophylactic mastectomy in breast cancer patients. Int J Clin Exp Pathol, 2015; 8 (4): 37483764.

23. Glassey R, Ives A, Saunders C, Hardcastle, S. Investigators influences on decisionmaking for young women undergoing bilateral prophylactic mastectomy. Patient Educ Couns., 2017; S0738-3991(17): 30482-2.

24. Roder $\mathrm{D}$, Zorbas, $\mathrm{H}$, Kollias $\mathrm{J}$ et al. Factors predictive of immediate breast reconstruction following mastectomy for invasive breast cancer in Australia. The Breast, 2013; 12201225.23.

25. Jeevan, R, Cromwell, DA, Browne, JP et al. Findings of a national comparative audit of mastectomy and breast reconstruction surgery in England. Journal of Plastic, Reconstructive \& Aesthetic Surgery, 2014; 67: 1333-1344.

26. Sisco, M, Du, H, Warner, JP, Howard, MA, Winchester, DP, Yao, K. Have We Expanded the Equitable Delivery of Postmastectomy Breast Reconstruction in the New Millennium? Evidence from the National Cancer Data Base. J Am Coll Surg, 2012; 215: 658-667.

27. Butler, P, Familusi, O, Serletti, J,M, Fox, J,P. Influence of race, insurance status, and geographic access to plastic surgeons on immediate breast reconstruction rates. The American Journal of Surgery, 2017; 1-8.

Chang, $\mathrm{H}$. Trend in Performing Mastectomy for Breast Cancer Treatment and Prevention. Clinics in Oncology, 2016; 1(1168): 1-4.

28. Flitcroft K, Brennan, M, Costa, D, Spillane, A. Documenting patterns of breast reconstruction in Australia: The national picture. Breast, 2016; 30: 47-53.5.

29. Albornoz, CR, Bach, PB, Mehara, BJ et al. A Paradigm Shift in U.S. Breast Reconstruction: Increasing Implant Rates. Plastic and Reconstruction Surgery, 2013; 131(15): 15-23. 
Table 1. Characteristics of women receiving different surgical treatments.

\begin{tabular}{|c|c|c|c|c|c|c|c|c|}
\hline \multirow[t]{2}{*}{ Factors } & \multicolumn{2}{|c|}{$\begin{array}{l}\text { No primary } \\
\text { surgery }\end{array}$} & \multicolumn{2}{|c|}{ BCS } & \multicolumn{2}{|c|}{ Mastectomy } & \multirow{2}{*}{$\begin{array}{c}\text { Total } \\
\mathrm{N}\end{array}$} & \multirow[t]{2}{*}{$\begin{array}{c}\text { P-value } \\
\text { (Chi-square test) }\end{array}$} \\
\hline & $\mathrm{N}$ & $\%$ & $\mathrm{~N}$ & $\%$ & $\mathrm{~N}$ & $\%$ & & \\
\hline Register & & & & & & & & $<0.001$ \\
\hline Auckland & 354 & $3.8 \%$ & 4689 & $50.9 \%$ & 4175 & $45.3 \%$ & 9218 & \\
\hline Waikato & 116 & $4.5 \%$ & 1460 & $56.6 \%$ & 1004 & $38.9 \%$ & 2580 & \\
\hline Year of diagnosis & & & & & & & & 0.105 \\
\hline $2000-03$ & 133 & $4.7 \%$ & 1461 & $51.1 \%$ & 1266 & $44.3 \%$ & 2860 & \\
\hline $2004-06$ & 85 & $3.3 \%$ & 1323 & $51.9 \%$ & 1140 & $44.7 \%$ & 2548 & \\
\hline 2007-09 & 112 & $3.9 \%$ & 1477 & $51.6 \%$ & 1276 & $44.5 \%$ & 2865 & \\
\hline 2010-13 & 140 & $4.0 \%$ & 1888 & $53.6 \%$ & 1497 & $42.5 \%$ & 3525 & \\
\hline Ethnicity & & & & & & & & $<0.001$ \\
\hline Māori & 39 & $3.6 \%$ & 517 & $48.2 \%$ & 516 & $48.1 \%$ & 1072 & \\
\hline Pacific & 58 & $8.0 \%$ & 273 & $37.9 \%$ & 390 & $54.1 \%$ & 721 & \\
\hline Non- Māori/non-Pacific & 373 & $3.7 \%$ & 5359 & $53.6 \%$ & 4273 & $42.7 \%$ & 10005 & \\
\hline Age & & & & & & & & $<0.001$ \\
\hline$<40$ & 9 & $1.2 \%$ & 283 & $37.5 \%$ & 463 & $61.3 \%$ & 755 & \\
\hline $40-49$ & 31 & $1.2 \%$ & 1327 & $51.5 \%$ & 1219 & $47.3 \%$ & 2577 & \\
\hline $50-59$ & 39 & $1.2 \%$ & 1929 & $59.8 \%$ & 1258 & $39.0 \%$ & 3226 & \\
\hline $60-69$ & 37 & $1.3 \%$ & 1743 & $63.3 \%$ & 975 & $35.4 \%$ & 2755 & \\
\hline $70-79$ & 67 & $4.6 \%$ & 623 & $42.8 \%$ & 764 & $52.5 \%$ & 1454 & \\
\hline $80+$ & 287 & $27.8 \%$ & 244 & $23.7 \%$ & 500 & $48.5 \%$ & 1031 & \\
\hline Mode of detection & & & & & & & & $<0.001$ \\
\hline Not screen detected & 431 & $6.1 \%$ & 2827 & $39.8 \%$ & 3837 & $54.1 \%$ & 7095 & \\
\hline Screen detected & 39 & $0.8 \%$ & 3322 & $70.6 \%$ & 1342 & $28.5 \%$ & 4703 & \\
\hline Stage & & & & & & & & $<0.001$ \\
\hline Stage I & 99 & $1.8 \%$ & 3854 & $71.9 \%$ & 1404 & $26.2 \%$ & 5357 & \\
\hline Stage II & 264 & $5.8 \%$ & 1921 & $42.0 \%$ & 2385 & $52.2 \%$ & 4570 & \\
\hline Stage III & 107 & $5.7 \%$ & 374 & $20.0 \%$ & 1390 & $74.3 \%$ & 1871 & \\
\hline Public/Private & & & & & & & & $<0.001$ \\
\hline Private & 36 & $0.8 \%$ & 2751 & $60.2 \%$ & 1785 & $39.0 \%$ & 4572 & \\
\hline Public & 434 & $6.0 \%$ & 3398 & $47.0 \%$ & 3394 & $47.0 \%$ & 7226 & \\
\hline Deprivation & & & & & & & & $<0.001$ \\
\hline 1 to 2 (low deprivation) & 73 & $2.9 \%$ & 1402 & $55.7 \%$ & 1044 & $41.4 \%$ & 2519 & \\
\hline 3 to 4 & 77 & $3.9 \%$ & 1070 & $54.7 \%$ & 809 & $41.4 \%$ & 1956 & \\
\hline 5 to 6 & 89 & $3.5 \%$ & 1358 & $53.9 \%$ & 1074 & $42.6 \%$ & 2521 & \\
\hline 7 to 8 & 105 & $4.5 \%$ & 1211 & $51.4 \%$ & 1042 & $44.2 \%$ & 2358 & \\
\hline 9 to 10 (high deprivation) & 115 & $4.9 \%$ & 1055 & $45.2 \%$ & 1164 & $49.9 \%$ & 2334 & \\
\hline Unknown & 11 & $10.0 \%$ & 53 & $48.2 \%$ & 46 & $41.8 \%$ & 110 & \\
\hline Co-morbidity count & & & & & & & & $<0.001$ \\
\hline 0 & 176 & $1.9 \%$ & 5067 & $54.6 \%$ & 4036 & $43.5 \%$ & 9279 & \\
\hline 1 & 44 & $4.7 \%$ & 453 & $48.6 \%$ & 436 & $46.7 \%$ & 933 & \\
\hline $2+$ & 250 & $15.8 \%$ & 629 & $39.7 \%$ & 707 & $44.6 \%$ & 1586 & \\
\hline Total & 470 & $4.0 \%$ & 6149 & $52.1 \%$ & 5179 & $43.9 \%$ & 11798 & \\
\hline
\end{tabular}


Table 2. Odds ratio of having BCS compared to mastectomy.

\begin{tabular}{ccc}
\hline \multicolumn{1}{c}{ Factors } & P-value & OR (95\% Cl) \\
\hline $\begin{array}{c}\text { Co-morbidity count } \\
\text { 2+ vs 0 }\end{array}$ & 0.106 & $0.88(0.75-1.03)$ \\
Year of diagnosis & 0.086 & $0.89(0.78-1.02)$ \\
Register: Waikato vs Auckland & 0.360 & $1.00(0.98-1.01)$ \\
Age & $<0.001$ & $1.60(1.44-1.78)$ \\
Ethnicity & $<0.001$ & $0.99(0.99-1.00)$ \\
Māori vs Non- Māori/non-Pacific & & \\
Pacific vs Non- Māori/non-Pacific & 0.971 & $1.00(0.86-1.17)$ \\
Public vs Private & 0.521 & $0.94(0.78-1.13)$ \\
Deprivation & $<0.001$ & $0.70(0.64-0.77)$ \\
3-4 vs 1-2 & & \\
5-6 vs 1-2 & & $1.00(0.87-1.14)$ \\
7-8 vs 1-2 & 0.978 & $0.97(0.85-1.10)$ \\
9-10 vs 1-2 & 0.635 & $0.94(0.82-1.08)$ \\
Stage II vs Stage I & 0.382 & $0.76(0.66-0.87)$ \\
Stage III vs Stage I & $<0.001$ & \\
Screen Detected vs Not screen & $<0.001$ & $0.36(0.33-0.39)$ \\
detected & & $0.13(0.11-0.15)$ \\
\hline
\end{tabular}


Table 3. Characteristics of women having immediate breast reconstruction following mastectomy.

\begin{tabular}{|c|c|c|c|c|c|c|c|c|c|}
\hline \multirow[t]{2}{*}{ Factors } & \multicolumn{2}{|c|}{$\begin{array}{c}\text { Total } \\
\text { reconstruction }\end{array}$} & \multicolumn{2}{|c|}{$\begin{array}{l}\text { DIEP and } \\
\text { TRAM Flap }\end{array}$} & \multicolumn{2}{|c|}{$\begin{array}{l}\text { Latissimus } \\
\text { Dorsi Flap }\end{array}$} & \multicolumn{2}{|c|}{$\begin{array}{l}\text { Expander } \\
\text { Rec and } \\
\text { Implant }\end{array}$} & \multirow{2}{*}{$\begin{array}{c}\text { P-value } \\
\text { (Chi-square } \\
\text { test) }\end{array}$} \\
\hline & $\mathrm{N}$ & $\%$ & $\mathrm{~N}$ & $\%$ & $\mathrm{~N}$ & $\%$ & $\mathrm{~N}$ & $\%$ & \\
\hline Register & & & & & & & & & $<0.001$ \\
\hline Auckland & 789 & $18.9 \%$ & 363 & $46.0 \%$ & 47 & $6.0 \%$ & 379 & $48.0 \%$ & \\
\hline Waikato & 183 & $18.2 \%$ & 71 & $38.8 \%$ & 84 & $45.9 \%$ & 28 & $15.3 \%$ & \\
\hline Year of diagnosis & & & & & & & & & $<0.001$ \\
\hline $2000-03$ & 217 & $17.1 \%$ & 147 & $67.7 \%$ & 43 & $19.8 \%$ & 27 & $12.4 \%$ & \\
\hline 2004-06 & 195 & $17.1 \%$ & 92 & $47.2 \%$ & 29 & $14.9 \%$ & 74 & $37.9 \%$ & \\
\hline 2007-09 & 250 & $19.6 \%$ & 98 & $39.2 \%$ & 19 & $7.6 \%$ & 133 & $53.2 \%$ & \\
\hline 2010-13 & 310 & $20.7 \%$ & 97 & $31.3 \%$ & 40 & $12.9 \%$ & 173 & $55.8 \%$ & \\
\hline Ethnicity & & & & & & & & & $<0.001$ \\
\hline Māori & 54 & $10.5 \%$ & 27 & $50.0 \%$ & 9 & $16.7 \%$ & 18 & $33.3 \%$ & \\
\hline Pacific & 37 & $9.5 \%$ & 16 & $43.2 \%$ & 1 & $2.7 \%$ & 20 & $54.1 \%$ & \\
\hline Others & 881 & $20.6 \%$ & 391 & $44.4 \%$ & 121 & $13.7 \%$ & 369 & $41.9 \%$ & \\
\hline Age & & & & & & & & & $<0.001$ \\
\hline$<40$ & 180 & $38.9 \%$ & 71 & $39.4 \%$ & 25 & $13.9 \%$ & 84 & $46.7 \%$ & \\
\hline $40-49$ & 389 & $31.9 \%$ & 174 & $44.7 \%$ & 46 & $11.8 \%$ & 169 & $43.4 \%$ & \\
\hline $50-59$ & 313 & $24.9 \%$ & 157 & $50.2 \%$ & 48 & $15.3 \%$ & 108 & $34.5 \%$ & \\
\hline $60-69$ & 84 & $8.6 \%$ & 31 & $36.9 \%$ & 11 & $13.1 \%$ & 42 & $50.0 \%$ & \\
\hline $70-79$ & 5 & $0.7 \%$ & 1 & $20.0 \%$ & 1 & $20.0 \%$ & 3 & $60.0 \%$ & \\
\hline $80+$ & 1 & $0.2 \%$ & & & & & 1 & & \\
\hline \multicolumn{10}{|l|}{ Mode of detection } \\
\hline $\begin{array}{c}\text { Not screen } \\
\text { detected }\end{array}$ & 639 & $16.7 \%$ & 294 & $46.0 \%$ & 88 & $13.8 \%$ & 257 & $40.2 \%$ & $<0.001$ \\
\hline Screen detected & 333 & $24.8 \%$ & 140 & $42.0 \%$ & 43 & $12.9 \%$ & 150 & $45.0 \%$ & \\
\hline Stage & & & & & & & & & $<0.001$ \\
\hline Stage I & 344 & $24.5 \%$ & 134 & $39.0 \%$ & 50 & $14.5 \%$ & 160 & $46.5 \%$ & \\
\hline Stage II & 435 & $18.2 \%$ & 200 & $46.0 \%$ & 56 & $12.9 \%$ & 179 & $41.1 \%$ & \\
\hline Stage III & 193 & $13.9 \%$ & 100 & $51.8 \%$ & 25 & $13.0 \%$ & 68 & $35.2 \%$ & \\
\hline Public/Private & & & & & & & & & $<0.001$ \\
\hline Private & 558 & $31.3 \%$ & 301 & $53.9 \%$ & 61 & $10.9 \%$ & 196 & $35.1 \%$ & \\
\hline Public & 414 & $12.2 \%$ & 133 & $32.1 \%$ & 70 & $16.9 \%$ & 211 & $51.0 \%$ & \\
\hline Deprivation & & & & & & & & & $<0.001$ \\
\hline 1 to 2 & 265 & $25.4 \%$ & 135 & $50.9 \%$ & 22 & $8.3 \%$ & 108 & $40.8 \%$ & \\
\hline 3 to 4 & 188 & $23.2 \%$ & 76 & $40.4 \%$ & 14 & $7.4 \%$ & 98 & $52.1 \%$ & \\
\hline 5 to 6 & 199 & $18.5 \%$ & 81 & $40.7 \%$ & 34 & $17.1 \%$ & 84 & $42.2 \%$ & \\
\hline 7 to 8 & 173 & $16.6 \%$ & 81 & $46.8 \%$ & 30 & $17.3 \%$ & 62 & $35.8 \%$ & \\
\hline 9 to 10 & 133 & $11.4 \%$ & 52 & $39.1 \%$ & 30 & $22.6 \%$ & 51 & $38.3 \%$ & \\
\hline Unknown & 14 & $30.4 \%$ & 9 & $64.3 \%$ & 1 & $7.1 \%$ & 4 & $28.6 \%$ & \\
\hline $\begin{array}{l}\text { Comorbidity } \\
\text { count }\end{array}$ & & & & & & & & & $<0.001$ \\
\hline 0 & 901 & $22.3 \%$ & 410 & $45.5 \%$ & 120 & $13.3 \%$ & 371 & $41.2 \%$ & \\
\hline 1 & 48 & $11.0 \%$ & 18 & $37.5 \%$ & 7 & $14.6 \%$ & 23 & $47.9 \%$ & \\
\hline $2+$ & 23 & $3.3 \%$ & 6 & $26.1 \%$ & 4 & $17.4 \%$ & 13 & $56.5 \%$ & \\
\hline Total & 972 & $18.8 \%$ & 434 & $44.6 \%$ & 131 & $13.5 \%$ & 407 & $41.8 \%$ & \\
\hline
\end{tabular}


Table 4. Odds ratio of having immediate reconstruction or not after mastectomy.

\begin{tabular}{|c|c|c|}
\hline Factors & P-value & OR (95\% Cl) \\
\hline \multicolumn{3}{|l|}{ Ethnicity } \\
\hline $\begin{array}{c}\text { Māori vs Non- Māori/non- } \\
\text { Pacific }\end{array}$ & $<0.001$ & $0.53(0.38-0.73)$ \\
\hline $\begin{array}{c}\text { Pacific vs Non- Māori/non- } \\
\text { Pacific }\end{array}$ & $<0.001$ & $0.46(0.31-0.67)$ \\
\hline Public vs Private & $<0.001$ & $0.43(0.36-0.51)$ \\
\hline \multicolumn{3}{|l|}{ Deprivation } \\
\hline $3-4$ vs $1-2$ & 0.355 & $0.89(0.70-1.14)$ \\
\hline $5-6$ vs $1-2$ & 0.116 & $0.82(0.65-1.05)$ \\
\hline $7-8$ vs $1-2$ & 0.226 & $0.85(0.66-1.10)$ \\
\hline $9-10$ vs $1-2$ & $<0.001$ & $0.59(0.45-0.78)$ \\
\hline $\begin{array}{l}\text { Radiotherapy vs no } \\
\text { radiotherapy }\end{array}$ & 0.006 & $0.76(0.62-0.92)$ \\
\hline $\begin{array}{l}\text { Register: Waikato vs } \\
\text { Auckland }\end{array}$ & 0.002 & $1.41(1.14-1.75)$ \\
\hline \multicolumn{3}{|l|}{ Stage } \\
\hline Stage II vs Stage I & 0.012 & $0.78(0.64-0.95)$ \\
\hline Stage III vs Stage I & $<0.001$ & $0.52(0.40-0.68)$ \\
\hline \multicolumn{3}{|l|}{ Co-morbidity count } \\
\hline 1 vs 0 & 0.069 & $0.73(0.51-1.03)$ \\
\hline $2+$ vs 0 & $<0.001$ & $0.36(0.23-0.57)$ \\
\hline $\begin{array}{l}\text { Screen Detected vs Not } \\
\text { screen detected }\end{array}$ & $<0.001$ & $1.87(1.55-2.26)$ \\
\hline Age & $<0.001$ & $0.91(0.90-0.92)$ \\
\hline Year of diagnosis & 0.012 & $1.03(1.01-1.05)$ \\
\hline
\end{tabular}

